\title{
A qualidade dos alimentos: análise de algumas categorias da dietética popular
}

\author{
Quality of foods: analysis of some folk \\ dietary categories
}

Ana Maria CANESQUI ${ }^{1}$

RESUMO

O artigo aborda os conhecimentos dietéticos tradicionais expressos nas seguintes categorias: "quente/frio"; "forte/fraco" e "reimoso", que definem a qualidade e a propriedade dos alimentos e da comida e os seus efeitos sobre o corpo. Vale-se da literatura antropológica nacional e dos estudos qualitativos produzidos desde 1975 a 2005. Os estudos antigos são mais abundantes do que os atuais e, apesar dessa limitação, o artigo contribui para discutir as diferentes abordagens conceituais usadas pelos autores e demonstra a persistência do saber dietético tradicional, que convive com o saber científico da nutrição, sendo importante não desprezá-lo nas intervenções nutricionais.

Termos de indexação: alimentação; dietética popular; propriedades dos alimentos; qualidade dos alimentos.

\section{A B S T R A C T}

The article analyses the traditional dietary knowledge expressed in the following categories: "hot/cold"; "strong/ weak" and "reimoso" (watery) which define food quality and properties and its effects on the body. The discussion originates from Brazilian anthropological and qualitative studies published from 1975 to 2005. Old studies are more abundant than current ones and, in spite of this limitation, the article contributes to discuss conceptual approaches utilized by authors and demonstrates that traditional dietary knowledge survives with the scientific knowledge on nutrition. Therefore, it is important not to reject them in nutritional interventions.

Indexing terms: feeding; folk diet; food's properties; food quality.

\section{N T R O D U Ç Ã O}

A comida não é ingerida apenas por razões nutricionais, apesar de ela preencher necessidades vitais e biológicas fundamentais que garantem a própria vida e sobrevivência dos seres humanos. São bastante complexos os condicionantes que interferem na alimentação, que combinam uma

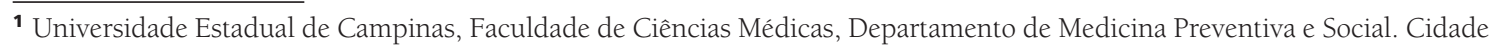
Universitária Zeferino Vaz, Caixa Postal 6111, 13084-971, Campinas, SP, Brasil.
} 
multiplicidade de fatores e a interdependência entre o homem biológico, o homem social e o cultural.

A nutrição, na história da humanidade, é mais do que prover energia e abarca tanto os processos físicos e corporais quanto a dimensão imaginária dos homens em relação aos alimentos. $\mathrm{O}$ ato de se alimentar gera estruturas de crenças e representações que não se desfazem com os progressos da ciência e com ela convivem. $\mathrm{Na}$ provisão dos alimentos também são estabelecidas as relações dos homens entre si e com o ambiente, que se modifica em virtude do trabalho humano e das aplicações das tecnologias na produção dos meios de sobrevivência e das trocas subseqüentes.

A antropologia tem contribuído para demonstrar a existência de outras formas de pensar e classificar os alimentos que não em termos de nutrientes, segundo o modelo da moderna ciência da nutrição. Os diferentes grupos sociais, submersos nas próprias tradições e em diferentes matrizes culturais, possuem conhecimentos dietéticos tradicionais acumulados que lhes foram transmitidos pelas gerações anteriores ou pelos agentes de cura tradicionais. Esses conhecimentos sobre o valor da dieta expressam-se por intemédio da linguagem, mantêm-se, transformam-se, convivem com os da Nutrição - calcados no saber científico - e foram estudados etnograficamente junto aos segmentos das classes populares em diferentes partes do Brasil.

Não é recente a abordagem socioantropológica da alimentação, podendo-se, no caso brasileiro, retomar pioneiros, como Gilberto Freyre ${ }^{1}$ e os folcloristas, dos quais se destaca Câmara Cascudo ${ }^{2}$, passando-se, nesse percurso, por alguns médicos clínicos, como Mello \& Silva ${ }^{3}$ ou pelos nutrólogos sociais, ao lado de Thales de Azevedo ${ }^{4}$ e de outros antropólogos, estudiosos de comunidades que, desde a década de $1940^{5}$, abordaram os orçamentos familiares, hábitos, proibições e tabus alimentares relacionados à gestação, ao parto e puerpério de várias populações nacionais.

Pode-se também retroceder, no plano internacional, à segunda metade do século XIX para recuperar, no contexto inglês, os pioneiros estudos antropológicos sobre a alimentação, incluindo tabus, totemismo, sacrifício e comunhão, no clássico trabalho de Sir James Frazer (1854-1941), referidos na nona edição da Enciclopédia Britânica e, posteriormente, no seu livro $\mathrm{O}$ Ramo de Ouro, em 1890, quando perguntou se todos os alimentos comestíveis são comidos ou se existem certos alimentos proibidos, temas que inspiraram, posteriormente, outros antropólogos sociais da escola de Cambridge, entre eles Malinowski, sobre as relações entre os tabus do sexo e a comida ${ }^{6}$. Após a publicação de Richards ${ }^{7}$, que foi discípula de Malinowski, o assunto não foi abordado na antropologia britânica até a década de 1960, sendo que Mintz \& Dubos ${ }^{8}$ mostraram a ampla bibliografia disponível naquele país.

Seria possível adentrar a antropologia cultural norte-americana e os pioneiros estudos sobre os hábitos alimentares, feitos na década de 1930-1940, e o subseqüente e amplo desenvolvimento especializado da antropologia nutricional nos Estados Unidos, combinando a interação do biológico e do ecológico com o sociocultural ${ }^{9}$, completando-se com o expressivo desenvolvimento da antropologia da alimentação em outros países europeus, além da Inglaterra, como a Itália, a França e a Espanha, que possuem importantes estudos históricos, antropológicos e sociológicos sobre a alimentação.

Toma-se como fulcro desse ensaio a análise de uma parcela das categorias da dietética popular, pela leitura das informações reunidas nos estudos etnográficos, feitos junto às classes trabalhadoras em diferentes partes do País, desde a década de 1970 até o momento. Parte-se da bibliografia disponível (artigos, teses, livros) específica ou mais geral, que se referiu às categorias alimentares, nos estudos antropológicos e qualitativos realizados sobre os vários assuntos, tais como: representações e práticas de saúde; alimentação; corpo e doença; estratégias de sobrevivência e consumo; hábitos e ideologias alimentares e simbolismo da comida. Retomam-se seletivamente algumas categorias mais freqüen- 
temente abordadas nos estudos etnográficos (o "quente/frio"; o "forte/fraco" e o "reimoso"), ancoradas nos conhecimentos tradicionais que se embutem nas representações e práticas (formas de pensamento ou idéias e ações), como integrantes de um conjunto de crenças que conformam a ideologia alimentar.

As diferentes situações etnográficas pesquisadas e publicadas permitem verificar as regularidades e variações na forma de classificar os alimentos, deparando-se, nos estudos examinados, com diferentes abordagens conceituais na análise daquelas categorias. Não se trata de abordar os referenciais teórico-metodológicos utilizados pelos autores, que são bastante heterogêneos e suscitam uma reflexão exclusiva e aprofundada, em um texto típico de revisão bibliográfica. Trata-se, de forma ensaística, de refletir sobre aquelas categorias, demonstrando as variações de seus conteúdos e entendimentos nos diferentes contextos brasileiros.

Boog $^{10}$, ao rever, recentemente, as pesquisas qualitativas no campo da alimentação e nutrição, observou o crescente interesse dos pesquisadores da área de saúde e nutrição na interlocução com a antropologia, reconhecendo a existência, no Brasil, de um campo específico dedicado à antropologia da alimentação, bem como a maior receptividade de estudos dessa natureza nos eventos científicos de nutrição, juntamente com a incorporação, por nutricionistas e enfermeiros, das abordagens qualitativas e dos referenciais das ciências sociais para pesquisar vários assuntos, tais como: a profissão de nutricionista, suas intervenções relativas à alimentação e nutrição, a educação nutricional, o comportamento, os hábitos ou as representações alimentares dos profissionais e de segmentos da população. Observa-se, contudo, nessa revisão, a ausência de estudos sobre as categorias dietéticas populares.

De fato há um acúmulo de estudos de antropologia e alimentação no Brasil, cujo volume oscilou bastante na produção bibliográfica, no período de 1970 até o momento. Nos anos de 1975 e 1976 foram realizadas etnografias sobre hábitos e ideologias alimentares em grupos de baixa renda no âmbito do convênio realizado entre a Financiadora de Estudos e Projetos (FINEP), Universidade Federal do Rio de Janeiro e Fundação Universidade de Brasília" ${ }^{11}$. Foi também criado o Grupo de Pesquisas de Ciências Sociais e Nutrição, financiado pela FINEP, pelo Instituto Brasileiro de Geografia e Estatística (IBGE) e pelo Instituto Nacional de Alimentação e Nutrição (INAN), que funcionou entre 1978 e o primeiro semestre de 1980, dedicando-se a outros estudos etnográficos sobre a alimentação, ao lado de análises específicas dos dados do Estudo Nacional de Despesas Familiar (ENDEF), realizado pelo IBGE em 1974-1975².

O interesse antropológico na alimentação foi menor na década de 1980, no Brasil, ainda que pesquisas tenham sido publicadas no seu decorrer. O assunto recrudesceu a partir da década de 1990 nos debates e fóruns de pesquisa antropológica, ao lado da maior expansão da antropologia no campo da saúde ${ }^{5,13,14}$. É provável que os interesses dos segmentos econômicos no turismo também tenham concorrido para incentivar o debate sobre a gastronomia e culinária, ao lado das práticas alternativas de certos grupos sociais, incluindo a alimentar naturalista ${ }^{15}$. Contudo, as publicações antropológicas nacionais se enriqueceram recentemente, com novas contribuições sobre comida e simbolismo e identidade, destacando-se alguns autores ${ }^{16-20}$ e outros mencionados na recente revisão bibliográfica sobre o assunto, comentada por Canesquii ${ }^{21}$, que inclui, entre outros assuntos, os estudos das tradições rituais e religiosas da alimentação consolidadas há longo tempo, compondo esse conjunto um acervo culinário importante, como matéria eminentemente cultural.

O debate acadêmico ampliou-se nos fóruns específicos de antropologia, por meio da criação do Grupo de Comida e Simbolismo da Associação Brasileira de Antropologia, que reúne uma rede de pesquisadores. Foi convocado o Grupo de Trabalho intitulado Saberes e Práticas da Alimentação, que substitui a designação anterior, 
para a 25a reunião da Associação Brasileira de Antropologia realizada em Goiânia em 2006. Reafirma-se, dessa forma, o maior interesse dos antropólogos no assunto, por meio dos fóruns de pesquisa, reunidos nas várias reuniões da Associação Brasileira de Antropologia, como as ocorridas em Salvador (1996), Brasília (2000), Gramado (2002) e Olinda (2004). O diálogo interdisciplinar amplia-se, atualmente, na criação da Sessão Brasileira da International Comission on Anthropology of Food (ICAF-Brasil) e do Grupo de Antropologia da Alimentação Brasileira22.

Não sendo novos a interlocução e o interesse das ciências sociais em saúde com a Nutrição, no âmbito da saúde pública/saúde coletiva, observam-se propostas de intervenção voltadas à promoção da saúde ${ }^{23}$, para o controle das doenças crônicas não transmissíveis, entre elas o diabettes mellitus e a hipertensão, cujas estratégias incluem mudanças nos estilos de vida, destacando--se as modificações na dieta ${ }^{24}$. Essas não são tão fáceis de ser obtidas, à medida que a comensa-lidade contemporânea consolida-se num complexo de determinantes macroeconômicos, políticos, culturais e psicossociais ${ }^{25}$.

Apesar dos esforços de divulgação das informações nutricionais e do impacto da ciência, em matéria de nutrição, o imaginário, as representações e os saberes tradicionais continuam a funcionar plenamente, sendo que a ciência e o imaginário não se excluem mutuamente no universo da cultura ${ }^{26}$. Para o pesquisador francês Fischler ${ }^{27}$, o homem é um onívoro que se alimenta de carne, vegetais e de imaginário. Por essa razão, é preciso estar atento àquelas dimensões, embora os profissionais de saúde e da nutrição, que detêm os saberes e práticas da ciência nutricional enfrentem, permanentemente, nas suas intervenções, outras tradições dietéticas que serão abordadas a seguir.

\section{O "quente" e o "frio"}

Em várias regiões do Brasil os alimentos ainda são classificados em "quentes" e "frios", que são qualidades não relacionadas à temperatura, designadas por Peirano ${ }^{28}$ como quente/frio/ qualidade, que se completa por uma outra, a do quente/frio/temperatura, em torno das quais estão restrições e proibições alimentares e comportamentais. Vários estudos latino-americanos e nacionais reportaram-se a essas categorias, cujo emprego é heterogêneo nas diversas regiões do País ou entre os informantes, sendo que um alimento pode ser "quente" em uma região e "frio" em outra11.

Assim, por exemplo, a carne de porco era "fria" no Pará29 e era "quente" para os lavradores urbanizados de Mossâmedes, em Goiás ${ }^{30}$, e para os trabalhadores de Paulínia, no interior do Estado de São Paulo ${ }^{31}$, bem como para os caiçaras do litoral Paulista ${ }^{32}$. No Pará era "frio" o animal que vivia no barro ou dele se alimentasse ou que possuísse carne branca, enquanto em Goiás eram "frias" as verduras em geral, certas frutas, legumes ou raízes (melancia, tomate, lima, mandioca), da mesma forma que em Paulínia, lima e melancia incluíam-se nessa categoria.

No Pará, eram "quentes" os animais de carne amarelada ou vermelha (certos peixes), os sangüíneos ou aqueles que possuíam cascos. Em Mossâmedes ${ }^{30}$ eram "quentes" os animais de caça (mais os mamíferos e menos as aves), o ovo e algumas verduras, legumes e frutas (quiabo, abóbora, pequi, laranja Bahia, pimenta e manga). Os paulinienses ${ }^{31}$ incluíam naquela categoria o feijão, a manga, a pimenta, pimentão e amendoim, enquanto, entre os caiçaras, alho, cebola, pimenta, café, amendoim, abacate, manga e mel eram "muito quentes", tal como a carne de porco para os goianos e paulinienses. Os goianos ${ }^{30}$ classificavam como alimentos neutros ("nem quentes" e "nem frios") o leite, a carne de gado, certas aves domésticas, batata, por não serem "ofensivos" ao organismo, enquanto os paulinienses consideravam o arroz e a batata nessa categoria.

Observou-se, nas respostas de 506 informantes de Porto Nacional (Goiás), pesquisados por Campos ${ }^{33}$, a classificação simultânea de alimentos, em uma e outra categoria, cuja variabi- 
lidade individual e a falta de unanimidade ficaram evidentes. A lima, a banana e a coalhada foram classificadas como "frias" por 70,0\% dos respondentes, enquanto uma proporção de respostas, oscilando entre $4,3 \%$ e $8,1 \%$, referiu-se a elas como "quentes", e os demais entrevistados não forneceram informações. Para 70,0\% dos informantes eram "quentes" o pequi, a carne de porco, a gordura de coco, enquanto $6,0 \%$ a $7,0 \%$ deles os consideravam "frios", e o restante não prestou informação. Essa variabilidade nas respostas é sempre mencionada pelos diferentes autores.

A literatura antropológica, na linha culturalista, abordou na medicina tradicional a relação entre alimentação, corpo e doenças, por meio da síndrome quente-frio. Essa classificação aplica-se ao corpo e suas partes, às doenças, aos alimentos, aos remédios e às ervas, associando-se, em certas regiões, aos poderes simbólicos e sobrenaturais ${ }^{34}$. Para alguns autores trata-se de teoria médico-popular, isto é, um conjunto de crenças da medicina antiga sobre o equilíbrio harmônico entre dois ou mais elementos ou forças opostas. O equilíbrio depende de forças externas (a alimentação ou o ambiente, o clima e os agentes sobrenaturais) e internas, sempre referidas nos estudos das crenças populares sobre a causalidade das doenças.

Foster ${ }^{35}$ foi um dos primeiros antropólogos a analisar a síndrome do quente-frio como uma crença médica antiga, sobrevivente nas várias populações latino e centro-americanas, originária da medicina hipocrática humoral grega, que concebe o corpo humano composto de substâncias que são os humores (sangue, fleuma, a bile amarela e bile preta) e suas respectivas qualidades: quente, fria, seca e úmida. Tanto a alimentação, quanto o meio ambiente e as estações do ano são forças externas que afetam o equilíbrio dos humores, cuja recuperação de sua porção ideal se dá com o auxílio das dietas alimentares, dos remédios especiais ou pela eliminação dos excessos, pelo uso de sangrias, purgantes, vômitos ou jejuns.

A medicina hipocrática grega foi uma das explanações sobre as doenças e o corpo na Grécia
Antiga, disseminou-se pelas influências dos romanos, percorreu outros países, incluindo o mundo árabe e também alcançou os mundos hispânico e ibérico e, pelas mãos dos colonizadores, difundiu-se para os diferentes países latinos e centro-americanos. Inúmeros estudos etnográficos latino-americanos e alguns nacionais endossaram as teses difusionistas de Foster ${ }^{35}$ da medicina humoral grega, enquanto outros evocaram as origens indígenas das categorias "quente" e "frio" que estiveram presentes nas formas de pensar dos "nativos", ao lado de outras oposições cosmológicas universais como a noite/o dia; o sol/a lua ou a mão direita/mão esquerda, o alto/baixo, que condensam elevados valores simbólicos, associando-se o "quente/frio" aos rituais xamanís$\operatorname{ticos}^{36}$. Esses autores refutaram a tese de que a teoria humoral grega tenha sido introduzida pelos colonizadores entre os indígenas. Admitiram a existência, prévia à colonização, de uma tradição humoral indígena na América do Sul, presente entre os grupos indígenas e as populações mestiças, habitantes da fronteira das Guianas, Venezuela e Brasil, pesquisadas por eles.

$\mathrm{Na}$ China, a medicina tradicional conta com idéias complexas sobre a concepção da fisiologia corporal, que relaciona a saúde ao equilíbrio dos dois princípios cósmicos contrastantes: o yin (escuro, úmido, aquoso e feminino) e o yan (quente, seco, masculino e fogoso). o primeiro governa o coração, os pulmões, o baço, os rins e o fígado e o segundo os intestinos, estômago e vesícula biliar37. A dicotomia "quente/frio", em torno de uma concepção vitalista do corpo de equilíbrio da energia vital, é evocada na explicação modificada daquela teoria, na China, na Malásia, em Hong Kong e em outros países asiáticos ${ }^{38}$, que atribuem grande importância à alimentação nas prescrições terapêuticas e na preservação do equilíbrio energético.

Ao rever os estudos de medicina popular no Brasil, Queiroz ${ }^{32}$ reporta-se à síndrome do quente/frio e à hipótese de sua transposição pelos jesuítas. O autor manteve-se crítico à tese culturalista-difusionista de Foster ${ }^{35}$ e pouco preocupado 
em especular sobre as origens daquela síndrome, que para ele integra-se à medicina naturalística, enquanto um sistema informal de pensamento e práticas. A medicina tradicional comporta a noção de equilíbrio entre o ser humano e os ambientes cosmológico e físico. As doenças, o corpo, os alimentos e remédios enquadram-se na lógica do "quente" e "frio" para os caiçaras estudados pelo autor.

A classificação dos órgãos e partes do corpo humano em "quentes/frios" e o correspondente uso de medicamentos e alimentos mantêm a harmonia do corpo, segundo as representações das classes populares. Os caiçaras, estudados por Queiroz $^{39}$ uniam, nas suas crenças, o corpo e a mente, contrariando a sua separação, segundo a filosofia de Descartes, presente na concepção mecanicista do corpo do modelo biomédico. Eles explicavam que a garantia da saúde requeria a manutenção da "cabeça fria" e o corpo "quente", sendo que o "nervoso" e a "violência" implicavam a subida do sangue ("quente") para a cabeça ("fria"), provocando o desequilíbrio corporal. Eles utilizavam vários critérios corporais (sensações de calor, digestão difícil, aumento da pressão sanguínea e "ataque" ao fígado) para classificar os alimentos como "quentes".

Ibanez-Novión ${ }^{40}$, referindo-se aos informantes da cidade de Sobradinho, mostrou que as doenças traduzem a ruptura do equilíbrio corporal e, da mesma forma que os alimentos, classificam-se em "frias" e "quentes", segundo sua origem e procedência, do interior ou do exterior do corpo. O autor endossou a tese do sistema de equilíbrio dos contrários, que indica a incompatibilidade de aplicar dietas alimentares "frias" às enfermidades "quentes" e vice-versa, pelo agravamento do estado de saúde ou mal-estar que essa prática pode ocasionar ao consumidor.

Ao se referir às categorias "quente/frio", aplicadas às partes e aos órgãos do corpo humano, o autor enfatiza a sua associação simbólica às cores. O vermelho ou o branco de certos órgãos associa-se ao vermelho de certos alimentos, como espectro simbolizante de sua força e expressão daquele equilíbrio. A oposição corpo/cabeça traduz-se nas representações do corpo, sendo a cabeça governada pelo miolo e o corpo pelo coração. A cabeça é o receptáculo das idéias e domínio, "sem sangue e frio", representado pela cor branca; enquanto o corpo contém sangue e é representado pela cor vermelha, sendo classificado como "quente" 40,41 . O corpo, para outros autores, refere-se à parte física, assim como a cabeça, além de ser sede das idéias, representa-se por suas qualidades morais ("ter cabeça no lugar"), sendo que o sangue é percebido como veículo de ligação entre ambos $^{42}$.

Rodrigues ${ }^{43}$ associa as categorias classificatórias dos alimentos ao corpo como expressão dos princípios da medicina hipocrática, endossando a tese de Forster ${ }^{35}$. O corpo sadio, nesse caso, explica-se pelo estado de equilíbrio interno com a ação externa, seja pelos esforços realizados, seja pelos alimentos absorvidos. Esses últimos, além de nutrirem, protegem e garantem a manutenção do equilíbrio corporal e, quando mal utilizados, podem agredir ou desequilibrar o corpo, gerando doenças.

Observa-se, em outros estudos etnográficos sobre as representações do corpo, a associação do fluxo menstrual com a fertilidade, que são pensados como estados do corpo ("quentes" e "úmidos"), e, por essa razão, os períodos menstruais tornam-se propensos à procriação, segundo as entrevistadas de Victora ${ }^{44}$, em Porto Alegre. As "chapoeiradas" (infusões contraceptivas populares, que combinam ervas diversas, canela, vinho fervido, caldo de feijão, cachaça, associando categorias de bebidas, temperos e comidas "quentes" e "fortes") baseiam-se nos princípios simpáticos da magia (do semelhante atuando sobre o semeIhante), cuja lógica combina pares de oposição e de associação que ordenam o corpo e a própria visão de mundo, cujo emprego preventivo é acompanhado de procedimento mágico ${ }^{45}$. Essa autora mostrou variações importantes das "chapoeiradas", pela incorporação de alimentos "fortes" (gordura, certos óleos e resinas, a fervura de pregos), que, associados ao vinho, mantêm a cor semelhante ao sangue, alusivo ao processo de procriação. 
Queiroz ${ }^{32}$ mencionou a recusa de alimentos "quente/frios" durante a gravidez, por eles afetarem o útero, enquanto os "muito quentes" (carne de porco, certos peixes e vegetais) podem provocar aborto. Os alimentos "frios" devem ser evitados para não provocarem distúrbios do sangue menstrual ou a sua retenção pelo organismo. Os efeitos na geração ou no agravamento de doenças, ocasionados pela ingestão de certos alimentos considerados "frios" ou da exposição do corpo à baixa temperatura ("tomar friagem" ou "banho frio" sempre referidos como comportamentos a serem evitados), foram observados em outras situações etnográficas, junto com prescrições de evitação de certas categorias de alimentos, durante a gravidez e puerpério, entre populações rurais e menos expostas aos serviços de saúde, cujas regras aplicam-se de maneira flexível e variada.

Mudanças bruscas de temperatura corporal, pela exposição ao ambiente frio ou quente (quente/frio/térmico), deviam ser evitadas pelos operários da construção civil ${ }^{41}$, que atribuíam as gripes e o reumatismo à exposição do corpo quente à baixa temperatura climática (friagem) ou à chuva, após intenso uso no trabalho. O desequilíbrio entre o "quente/frio" no corpo podia ser provocado pela ingestão de alimentos ou bebidas "frios" ou "quentes" que deviam ser evitados como, por exemplo, ingerir uma fruta aquecida pelo sol ou tomar bebidas "quentes", como o café, e expor, a seguir, o corpo a ambientes de baixa temperatura ${ }^{1}$.

Se a percepção do corpo conduz à diferenciação de gênero, como disse Woortman ${ }^{46}$, à medida que a mulher é vista como possuidora de dois órgãos relacionados ao corpo (o coração e o útero), ela é considerada mais "quente" do que o homem e, por essa razão, tendente ao desequilíbrio. A mulher, pelo fato de possuir útero, é percebida como tendo mais sangue que o homem e possuidora de natureza "quente". O estado de equilíbrio do corpo feminino está em permanente perigo de ruptura, especialmente durante a gravidez e o ciclo menstrual 29,40 .

Ao quente/frio/térmico, Peirano ${ }^{28}$ atribuiu, entre pescadores do litoral cearense, regras de proibições alimentares, da mesma forma que os alimentos como "quentes" e "frios", independentemente da temperatura, possuíam efeitos sobre o corpo, sendo que os itapuaenses do Pará atribuíam certas doenças (congestão, impaludismo, gripes e resfriados) à quebra das regras de proibições alimentares relacionadas ao quente/frio/ térmico, enquanto a inobservância das proibições relativas ao quente/frio/qualidade, apenas agravava certos estados corporais ou doenças ${ }^{47}$.

Alimentos "quentes", geralmente, são ofensivos ao aparelho digestivo, descontrolando especialmente os intestinos; enquanto os alimentos "neutros" não são considerados nocivos à saúde, os alimentos "frios" podem agravar seriamente os estados gripais e os resfriados ${ }^{30}$. Esse autor observa que o informante, ao ser pressionado para apresentar os motivos para a posição dos alimentos em uma ou outra categoria, associa o "quente" ao "forte" e ao "reimoso", não apresenta nenhuma explicação mais completa sobre o "frio" e expõe os malefícios que faz aos pulmões.

\section{A força e a fraqueza; os alimentos "fortes" e "fracos"}

As categorias força e fraqueza foram abordadas nos estudos de representações do corpo, saúde e doença e ocuparam uma boa parte das pesquisas etnográficas e qualitativas em saúde no Brasil, nas décadas de 1980 e 1990. São categorias bastante recorrentes nos discursos populares para se referir aos alimentos e aos estados corporais, e à própria pessoa. A doença, no discurso das camadas populares, tanto se associa à incapacidade de usar o corpo no trabalho e nas atividades em geral, quanto é percebida pelas sensações de "fraqueza" e "desânimo", vagamente descritas, contrariando a lógica do discurso médico.

Para Minayo ${ }^{48}$, as representações (idéias) de saúde e doença das classes populares remetem a dimensões sociais e individuais, envolvendo significações culturais e relações sociais, como manifestação das contradições e lutas sociais, 
sendo também totalizantes, por envolverem o corpo, a alma e o espírito. O significado da doença, diz Knauth ${ }^{42}$, remete à ordem social, uma vez que ameaça não apenas o indivíduo na sua reprodução biológica, mas a reprodução social, as condições de sua existência social.

A "fraqueza" aplica-se, tanto à percepção dos estados corporais ("fraqueza física") quanto ao enfraquecimento mental e corporal de adultos e crianças, associado à fome ou aos comportamentos abusivos, que podem fragilizar ou desequilibrar o organismo, como o uso de bebidas alcoólicas e de certas comidas ${ }^{49}$. Aquela categoria associa-se, simbolicamente, à idéia de fraqueza moral da pessoa perante a sociedade, expressando também as desordens ou a anomia social ${ }^{50}$, assim como as diferenças sociais e de poder na sociedade, entre ricos e pobres ${ }^{31}$, que são pensadas a partir da comida acessível e obtida. Portanto, as dimensões física, social, moral, política, subjetiva e material conjugam-se nas representações da doença em um espectro múltiplo e bastante complexo de significados.

As representações da saúde nas camadas populares reúnem-se em torno da idéia de força (física e moral), da "disposição" para usar socialmente o corpo nas atividades cotidianas, sendo esse o meio indispensável para trabalhar, para os que dependem do uso da força corporal para sobreviver. A saúde remete à idéia de bem-estar, sendo tanto a ausência da doença, dos problemas, preocupações, sofrimentos e mal-estares, quanto o equilíbrio e a ordem nas distintas dimensões da vida, das relações sociais e do próprio corpo com o espírito. A idéia de saúde envolve a de paz, alegria e felicidade, com um sentido hedonista de vida ${ }^{51}$, enquanto, por oposição, a doença associa-se aos estados de tristeza, à infelicidade e às perturbações da vida, incorporando as dimensões físicas, morais e espirituais ${ }^{48,49}$.

Os estudos sobre representações de saúde e doença enfatizam a centralidade da alimentação nos setores populares, como garantia da aptidão para o trabalho e do uso intenso do corpo nessa atividade tão indispensável à sua sobrevivência, fato esse que se liga à posição de classe, sem deixar de ter relevância a importância atribuída ao gosto e ao prazer de comer que a comida encerra para aqueles grupos sociais. Ganham proeminência, nos discursos, "a falta de apetite" e de "vontade de comer" como sinais indicativos de algum mal-estar ou problema de saúde, que adquirem maior gravidade quando observados nas crianças. A alimentação, para as camadas populares, é uma atividade reparadora, tão importante quanto o sono. Portanto, "estar alimentado" implica saciedade física e "ser ou estar sadio", que coincide com a idéia de "ser forte" (resistente), sendo a alimentação uma fonte primordial de "sustança" para o corpo, de sobrevivência e de preservação da identidade social ${ }^{52}$.

As práticas de manutenção, prevenção e preservação da saúde, entre aqueles segmentos sociais cogitam associações importantes com as medidas higiênicas, o uso de medicamentos, os rituais e simpatias, o uso de amuletos ou de medaIhões para atrair a " boa sorte" e a " boa saúde"53, sendo que os exercícios físicos, o uso de dietas de emagrecimento, de medicamentos e os cuidados com a alimentação em geral também se associavam àquelas práticas entre os funcionários de uma universidade paulista ${ }^{54}$. A conservação da saúde implica a observância de um conjunto de normas que se traduz em prescrições morais, incluindo aquelas sobre a maneira regrada de comer, beber, dormir, vestir, trabalhar e de conduzir a vida em geral.

Um discurso em torno da "alimentação saudável" sobre os malefícios e benefícios de certos alimentos à saúde ("gordurosos, contaminados e com colesterol") e dos elos entre a alimentação e a doença, juntamente com o gosto e o prazer de comer, foram centrais nas representações de trabalhadores de escritório da cidade de São Paulo pesquisados por Garcia ${ }^{55,56}$. A associação de alimentos gordurosos, o consumo exagerado do sal, as preocupações e dificuldades da vida em geral, foram evocadas para explicar a hipertensão ("pressão alta", designação do senso comum) entre segmentos das classes populares 
no Recife ${ }^{57}$. Esses estudos demonstram os efeitos da divulgação das categorias de dietética científica e sua incorporação pelos diferentes segmentos sociais, embora a assimilação dos conteúdos das mensagens passe pelo processo de reinterpretação, segundo as matrizes culturais dos diferentes grupos sociais.

Os serviços de saúde e a mídia, geralmente, veiculam mensagens sobre o significado da alimentação saudável calcada no saber dietético erudito, e os entrevistados de Garcia ${ }^{55}$ centraram os seus discursos na importância da ingestão de frutas e verduras, por suas qualidades de concentrar "vitaminas", valorizando, simultaneamente, o corpo esbelto e magro, que são valores estéticos próprios das classes médias e altas, segundo Boltanski ${ }^{58}$. Esses valores contrapõem-se ao corpo "forte" e "gordo", como sinônimo de "sadio," geralmente referido pelas classes populares.

Os diferentes estudos apontam o fato de a carne de gado e o feijão preto serem considerados "fortes" (que saciam por um longo tempo e "matam a fome"), enquanto outros alimentos sofrem variações na sua classificação. Em Itapuá, PA, os "mais fortes" eram o café, o feijão, o leite, e os "menos fortes" eram o arroz, a batata doce e a carne de frango. Os "menos fracos" incluíam o caranguejo, o caramujo e o siri, enquanto os refrigerantes eram "mais fracos".

Em Mossâmedes e em Paulínia eram "fortes", a carne de gado, o feijão, o leite e o torresmo, e eram "fracos", o arroz, a batata e as verduras, e "nem fortes e nem fracos", a mandioca, a batata e o milho. Em Paulínia, as verduras "mais fortes" eram a couve, a chicória e as batatas (há dúvidas a respeito), juntamente com as bebidas alcoólicas (aguardente e cerveja). Os alimentos "fracos" eram o arroz, o macarrão, algumas verduras (chuchu e pepino) e certos doces e frutas. Em Paulínia e Mossâmedes, observou-se o emprego da categoria "vitamina" para se referir às frutas e verduras, sendo esse um termo aprendido com os profissionais de saúde, cujo significado se traduz na qualidade de "sustância" e "fortidão" dos alimentos e não à sua conceituação, nos termos do saber da nutrição científica.
As categorias "forte" e "fraco" também não se restringiam aos alimentos. Aplicavam-se ao corpo e suas partes, aos comportamentos morais, aos medicamentos (os antibióticos e tônicos são mais "fortes" do que outros remédios), aos elementos da natureza ("terra forte", "terra fraca"), aos animais e aos seres humanos (os homens são mais "fortes" do que as mulheres, e os adultos, mais "fortes" do que os idosos). Trata-se de uma classificação fundada na associação entre os graus de força dos alimentos com os graus de força (resistência) corporal de certo tipo de pessoa, concebida segundo a sua "natureza" "forte ou fraca", que são predisposições inatas. ${ }^{41}$, associadas às idéias naturalizadas sobre as condições físicas (anatômicas e funcionais do corpo) e morais (de caráter) da pessoa.

O jogo dessas oposições traduz-se em avaliações positivas ou negativas dos efeitos dos alimentos sobre o corpo e suas partes. Resume-se, abaixo, a exposição de Brandão (p.114) ${ }^{30}$, que pode ser aplicada a outros contextos pesquisados, por traduzir também a teoria do equilíbrio entre as forças internas, expressas na "natureza" da pessoa (forte ou fraca), com as externas (tipo de alimentação). Os alimentos, ao se incorporar ao corpo, podem manter ou alterar a "natureza" da pessoa, produzindo também efeitos no uso social do corpo ou nos seus estados. Veja-se a seguir:

Comida forte versus pessoa forte $=$ bom (mantém a resistência para o trabalho e protege contra a fome).

Comida fraca versus pessoa forte $=$ ruim ("tira a força da pessoa", fazendo-a perder, mesmo sem ficar doente, as qualidades da pessoa forte) ${ }^{30}$

Comida forte versus pessoa fraca $=$ ruim ("ofende" sobretudo o aparelho digestivo)

Comida fraca versus pessoa fraca $=$ bom (ajuda a recuperação de quem está doente e não "ofende" a quem é doente) $)^{30}$.

A alimentação interfere substantivamente sobre o sangue, segundo as representações 
populares, determinando a sua qualidade, sendo essa dimensionada pela aparência física, pela força ou fraqueza. Portanto, a natureza "forte" da pessoa, sendo inata, qualifica-se pelo sangue "forte" ("muito sangue" e "sangue bom") e a natureza "fraca", pelo sangue "ralo", associado à anemia, que se traduz na escassez de sangue, na aparência empalidecida, nas sensações de "falta de ânimo" e "fraqueza" generalizada.

O sangue é um símbolo multivocal, segundo Turner ${ }^{59}$, evocando muitos significados, tais como: a indicação de estados emocionais (rubor e palidez); tipo de personalidade (sangue quente/sangue frio); o parentesco (ser ou pertencer ao sangue); perigo (sangue menstrual e sangramento pós-parto); ferimentos físicos (hematomas e sangramentos) e alimentação ("sangue ralo", causado pela dieta inadequada) $)^{37}$, significando também a força vital.

Os estudos etnográficos mostram a preferência das camadas populares pela "comida forte", por garantir resistência e aptidão para o trabalho e proteger contra a fome, prolongando a sensação de saciedade. A idéia de força, de "sustança", como qualidade de diferentes comidas, é fundamental nas representações populares. Alimentos "fortes" e "pesados", que "sustentam" e transmitem a sensação de saciedade (feijão, carne de vaca, massas, milho) eram sempre os preferidos $^{60,31}$.

Em oposição, "comidas ou alimentos fracos" são vistos como destituídos de "sustança", associam-se à leveza e à não-saciedade, à não-perturbação do equilíbrio corporal ou da digestão, não sendo excluídas, por essas razões, dos cardápios cotidianos. Eles demarcam a identidade do ser pobre, sendo expressão simbólica de uma dieta empobrecida e da condição de pobreza, da mesma forma que o consumo de alimentos, como o "bró", no Nordeste semi-árido, nos momentos de extrema seca e falta de alimentos, simbolizava os "tempos difíceis", de "sofrimento", a precariedade e miséria ${ }^{61}$.

\section{A "reima" e o "reimoso"}

A "reima" não é uma categoria classificatória amplamente disseminada, permeando os discursos dos pescadores, caboclos, indígenas ou agricultores pertencentes às regiões Norte, Centro-Oeste e Nordeste do País, ou dos migrantes oriundos dessas regiões. É uma categoria que carece de definição precisa. Rodrigues ${ }^{43}$ disse que o alimento é sempre 'reimoso' "para" (uma pessoa ou para o organismo) ou, segundo Brandão ${ }^{30}$, por seus efeitos prejudiciais ao sangue, à pele ou pela referência de sua simples presença no corpo das pessoas.

Maués \& Maués 29 associaram à "reima" um conjunto de situações liminares não caracterizadas como estados de saúde ou de doença (menstruação, gravidez, puerpério, luto e convalescença), às quais os itapauenses aplicavam as proibições alimentares, provocando situações de afastamento simbólico ou real das pessoas naquelas condições. Eles classificavam os alimentos em "mansos" (não causam nenhum mal) e "reimosos", que deviam ser evitados por pessoas doentes, em convalescença, luto e pelas mulheres naqueles estados liminares. Os autores lembram que as regras de proibição são flexíveis, podendo funcionar e ser manipuladas em certas situações, como mecanismos de defesa contra a fome, admitindo que o sistema de idéias não se desvincula das práticas sociais.

Sangue, corpo, comidas e certas espécies vegetais e animais possuem "reima", sem que exista uma regra geral nas classificações e nas interdições associadas ${ }^{30}$. Ao fixar as proibições e tabus alimentares em torno da "reima", Peirano28, diferentemente dos demais autores, endossou a tese estruturalista de Lèvi-Strauss, de que os alimentos são "bons para pensar", sendo que as classificações regem-se por modelos lógicos de ordenação conceitual que presidem as normas, proibições e os hábitos alimentares. São modelos abstratos e dicotômicos, como o par natureza/cultura. Assim, as proibições dos alimentos "reimosos" (certos peixes e animais caçados) 
expressam, para a autora, a relação de homologia entre os seres da natureza e os seres humanos, que se traduzem, no plano simbólico, em proibições de consumo daqueles alimentos por certas pessoas e nos impedimentos de suas aproximações.

Maués \& Maués ${ }^{29}$ analisaram a dimensão simbólica que impregna as classificações alimentares, sendo que os alimentos impuros ("reimosos") devem ser afastados de pessoas poluídas ou impuras, por estarem em certos estados liminares. Eles não restringiram a sua análise ao jogo das oposições polares e formais dos modos de pensar a relação natureza/cultura, e se referiram às situações e aos contextos sociais que fazem emergir as proibições dos alimentos "reimosos", especialmente nos rituais xamanísticos, sendo grande a potencialidade de a "reima" ser estendida e aplicada a inúmeras situações, no conjunto das relações sociais da sociedade itapuaense.

Para Rodrigues ${ }^{43}$, os alimentos e os comportamentos "reimosos" associam-se a certos estados corporais de circulação do fluxo de líquidos, que se aproximam dos humores, produzindo a "reima" efeitos sobre o equilíbrio corporal. O autor não se dá conta das mudanças e reinterpretações dessa teoria ao longo do tempo, enquanto Murrieta ${ }^{62}$ refere-se a vários sistemas que definem a "reima", segundo o gênero, idade, estado liminar, experiência pessoal, sendo o equilíbrio do corpo e do espírito alvo preferido das proibições da "reima", impostas a certos estados corporais (de doença, parto, pós-parto e menstruação) nas populações caboclas paraenses pesquisadas pelo autor. Costa-Net ${ }^{63}$ também confirma que, entre os pescadores do Litoral Norte baiano, os peixes de couro são "reimosos" e "carregados" e evitados por pessoas enfermas, que apresentam ferimentos corporais ou pelas mulheres, durante os eventos ligados à reprodução.

\section{CONSIDERAÇÕES FINAIS}

Observou-se, ao longo deste texto, a maior escassez de estudos nacionais recentes sobre as categorias alimentares tradicionais, que, contudo, não Ihes retira a sua importância no universo cultural da sociedade contemporânea, que comporta múltiplas matrizes heterogêneas. A análise das categorias alimentares abordadas neste trabalho, não pretendeu exaurir a totalidade delas, que abrange classificações alimentares, como os alimentos "pesados" e "leves", alimentos "com vitamina ou sem vitamina", entre outras, que expressam conhecimentos tradicionais e são repletas de significados. Elas se submetem às interpretações do senso comum, que se comunica com o conhecimento científico, reinterpretando-o, como exemplificam a categoria "comida saudável" e outras designações de nutrientes, utilizadas na linguagem do senso comum, que são emprestadas do discurso científico.

As categorias alimentares analisadas circunscreveram-se apenas às pesquisas qualitativas e antropológicas nacionais publicadas, empreendidas, principalmente, junto às camadas populares - que costumam ser mais freqüentemente abordadas pelos autores, do que pelos demais setores sociais -, tornando-se esse fato uma limitação dos estudos consultados, embora não se descarte a importância de abordá-las de maneira mais abrangente que a feita no âmbito deste artigo. São exemplares nesse sentido as comidas "naturais"; "orgânicas", além das categorias que permeiam as dietas alternativas, prescritas por outras medicinas (chinesa, indiana, homeopatia) que costumam ser mais acessíveis e apropriadas pelos segmentos médios e altos de nossa sociedade do que pelos populares.

Há uma multiplicidade de posições conceituais dos autores na abordagem das categorias alimentares, que ora são consideradas no âmbito das idéias e representações sociais - enquanto expressões ideológicas - não desvinculadas das práticas sociais, normas e regras culturais, ora aparecem sob a forma de conhecimento do senso comum, em uma abordagem de cunho mais fenomenológico ou ainda como parte do universo simbólico, seguindo a tradição de corte mais estruturalista ou mesmo como integrantes das tradições 
culturais, seguindo um dos conceitos de cultura. Apesar dessa diversidade, que não foi objeto de análise deste texto, destacam-se alguns pontos comuns.

O primeiro é que as categorias dietéticas não são exclusivas dos alimentos e comidas, aplicando-se a outras esferas da natureza, dos animais, dos vegetais, do corpo, da pessoa, das relações sociais e de outros produtos, como os medicamentos, sendo holístico o universo das representações populares.

O segundo aspecto refere-se à associação estabelecida entre o funcionamento corporal e o estado geral de equilíbrio com as propriedades dos alimentos e das normas sobre os seus usos, embora essas sejam flexíveis e altamente variáveis nos diferentes contextos pesquisados. A idéia de equilíbrio abarca tanto os efeitos dos alimentos sobre o funcionamento corporal quanto sobre a pessoa e suas qualidades morais, regendo-se pela idéia mais geral de ordem, entre forças externas e internas do funcionamento do corpo ou de suas partes e da própria pessoa.

O terceiro aspecto refere-se à variabilidade da inclusão dos alimentos nas diferentes categorias alimentares, que não obedecem a princípios fixos, sendo também flexíveis as regras de evitação dos alimentos, que são, freqüentemente, enunciadas e não observadas, requerendo esse fato a atenção dos pesquisadores nas coletas das informações.

A dietética tradicional impregna-se de representações, de conhecimentos, de explicações distintas da ciência nutricional, que não a torna irracional e sem lógica, como afirmam as posições etnocêntricas e intolerantes com as diferenças culturais. Para Lèvi-Straus ${ }^{64}{ }^{4}$, com o qual concordamos, o pensamento selvagem (que não se confunde com o do selvagem), é uma forma de pensar concreta, que observa, experimenta e classifica as coisas da natureza, detendo, portanto, a sua própria lógica. Na apreensão da alimentação e de seus efeitos sobre o corpo, essa forma concreta de pensar está presente entre os informantes, especialmente quando eles avaliam as propriedades da dieta ou o seu valor nutricional pelas sensações corporais. Certamente, as formas de pensar não se reduzem a meras operações lógicas, como queria aquele autor, enquanto manifestações exclusivas do espírito humano ou do pensamento, imunes à história, à práxis social, às sensibilidades, à experimentação e ao imaginário.

\section{REFERÊ NCIAS}

1. Freyre G. Problemas brasileiros de Antropologia Obras Escolhidas. Rio de Janeiro: Livraria José Olympio Editora; 1963.

2. Cascudo CL. História da alimentação no Brasil. 3a. ed. São Paulo: Global Editora; 2004

3. Mello ASA. Alimentação, instinto e cultura. Rio de Janeiro: Livraria José Olympio Editora; 1961. v.1. Coleção Documentos Brasileiros, 109.

4. Azevedo T. Um esquema de pesquisas etnográficas sobre alimentação. Rev Arq. 1940; 22(1):10-35.

5. Canesqui AM. Antropologia e alimentação. Rev Saúde Pública. 1988; 22(3):207-16.

6. Goody J. Cocina cuisine y classe. Estudo de sociologia comparada. Barcelona: Gedisa Editorial; 1982.

7. Richards A. Hunger and work in a savage tribe: a functional study on nutrition among the Southern Bantu. London: Rotledge; 1932.

8. Mints SW, Du Bois C. The Anthropology of food and eating. Ann Rev Anthr. 2002; 31: 99-119.

9. Messer E. Anthropological perspectives on diet Ann Rev Antr. 1984; 13:205-49.

10. Boog MCF. Pesquisa qualitativa no campo da alimentação e nutrição. In: Barros NF, Cecatti JG, Turato ER, editores. Pesquisa qualitativa em saúde. Múltiplos olhares. Campinas: Komedi; 2005. p.97-108.

11. Woortman AAWK. Hábitos e ideologias alimentares em grupos sociais de baixa renda. Brasília: Fundação Universidade de Brasília; 1978. Série Antropológica; 20.

12. Viaccava F, Figueiredo CMP, Oliveira WA. A Desnutrição no Brasil. Uma análise do Estudo Nacional da Despesa Familiar (IBGE 74-5) para o Nordeste, Estado de São Paulo e Estado do Rio de Janeiro. Rio de Janeiro: Vozes; 1983.

13. Canesqui AM. Os estudos de antropologia da saúde/doença no Brasil na década de 1990. Ci Saúde Coletiva. 2003; 8(1):109-18.

14. Minayo MCS. Construção da identidade da Antropologia na área da saúde: o caso brasileiro.In: 
Alves PC, Rabelo MC, organizadores. Antropologia da saúde.Traçando identidade e explorando fronteiras. Rio de Janeiro: Relume; 1998. p.29-46.

15. Lifschitz J. Alimentação e cultura: em torno ao natural. Physis-Rev Saúde Coletiva. 1997; 7(2): 69-83.

16. Collaço JHL. Restaurantes de comida rápida: soluções á moda da casa. Anais da 23a. Reunião Brasileira de Antropologia. Resumos. Gramado; 2002. p.5.

17. Rial CSM. Fast-foods: a nostalgia de uma estrutura perdida. Horizontes Antropológicos. 1996; 4:94-103.

18. Fry P. Feijoada e soul food 25 anos depois. In: Esterci $N$, et al. organizadores. Fazendo antropologia no Brasil. Rio de Janeiro: DP\&A; 2002. p.35-54.

19. Maciel ME. Churrasco à gaúcha. Horiz Antropol. 1996; 4:7-8

20. Góes JAW. Fast-food: espaço símbolo da supermodernidade. São Leopoldo; 2005. Disponível em: http://www.unisinos.br./ihu

21. Canesqui AM. Comentários sobre os estudos antropológicos da alimentação. In Canesqui AM, Garcia RWD, organizadores. Antropologia e nutrição: um diálogo possível. Rio de Janeiro: FIOCRUZ; 2005. p.23-47

22. Menasche R, Gomes LG. Proposta do grupo de trabalho representações e práticas de alimentação. Anais da 23a. Reunião da Associação Brasileira de Antropologia [acesso em 5 out 2005]. Disponível em: htpp://www.antropologias.com.br

23. Buss PM. Promoção da saúde e qualidade de vida. Ci Saúde Coletiva. 2000; 5(1):163-77.

24. Toscano CM. As campanhas nacionais para detecção das doenças crônicas não transmissíveis: diabetes e hipertensão arterial. Ci Saúde Coletiva. 2004; 9(4):885-93.

25. Garcia RWD. Reflexos da globalização na cultura alimentar:considerações sobre as mudanças na alimentação urbana. Rev Nutr. 2003; 16(4): 483-92.

26. Hubert A. Alimentation et santé: la science et l'imaginaire. Cah Nutr Diet. 2000; 35(5):353-6.

27. Fischler C. Presentation. Paris: Communications; 1979. p.1-3.

28. Peirano MGS. Proibições alimentares numa comunidade de pescadores [dissertação]. Brasília: Universidade de Brasília; 1975.

29. Maués H, Maués MA. O folclore da alimentação: Tabus alimentares da Amazônia. (Um estudo de caso numa população de pescadores do litoral Paraense) Belém: Falangola; 1980.

30. Brandão CR. Plantar, colher e comer. Rio de Janeiro: Graal; 1981.
31. Canesqui AM. Comida de rico, comida de pobre. Um estudo sobre alimentação num bairro popular [tese]. Campinas: Universidade Estadual de Campinas; 1976.

32. Queiroz MS. Teoria de lo cálido y lo fresco em la etiologia de las enfermedades em Brasil. In: Kroeger A, Cano WR, compiladores. Conceptos y tratamientos populares de algunas enfermedades em Latinoamerica. Peru: Centro de Medicina Andina; 1988. p.55-64.

33. Campos MS. Poder, saúde e gosto. Um estudo antropológico acerca dos cuidados possíveis com a alimentação e o corpo. São Paulo: Cortez; 1982.

34. Logan $\mathrm{MH}$. Selected references on the hot-cold theory of disease. Med Anthr New. 1975; 6:14-26.

35. Foster G. Hippocrates Latin american legacy: hot and cold in contemporary folk medicine. In: Wetherington RK, editor. Colloquia in Anthropology. 1976. p.3-19.

36. Colson AB, Armellada C. An amerindian derivation for Latin América creole illness and their treatment. Soc Sc Med. 1983; 17(12):1229-48.

37. Helman CG. Cultura, saúde e doença. Porto Alegre: Artes Médicas; 1994.

38. Currier RL. The hot-cold syndrom and symbolic balance Mexican and Spanish-American folk medicine. Ethn. 1966; 5.

39. Queiroz MS. Estudos sobre medicina popular no Brasil. Rel Soc. 1980; 5:241-50.

40. Ibãnez-Novión. El cuerpo, la enfermedad y su representación [dissertação]. Rio de Janeiro: Universidade Federal do Rio de Janeiro; 1974.

41. Costa AM. Riqueza de pobre: um estudo em antropologia da saúde [dissertação]. Brasília: Universidade Nacional de Brasília; 1980.

42. Knauth DR. Corpo, saúde, doença. Cad Antrop. 1992; 6:55-72.

43. Rodrigues AG. Buscando raízes. Horiz Antrop. 2001; 16:131-44.

44. Victora C. As imagens do corpo: representações o aparelho reprodutor feminino e a reapropriação de modelos médicos. In: Leal OF, organizador. Corpo e significado. 2a. ed. Porto Alegre: Universidade do Rio Grande do Sul; 2000. p.77-88.

45. Leal OF. Sangue, fertilidade e práticas anticonceptivas. In: Leal OF, organizador. Corpo e significado. 2a. ed. Porto Alegre: Universidade do Rio Grande do Sul; 2000. p.7-35.

46. Woortman AAWK. A comida, a família e a construção do gênero feminino. Dados. 1986; 29(1):103-30. 
47. Maués H. A llha encantada. Medicina e xamanismo numa comunidade de pescadores. Belém: Universidade Federal do Pará; 1990.

48. Minayo MCS. Pesquisa qualitativa em saúde: o desafio do conhecimento. São Paulo: Hucitec; 1992.

49. Duarte LFD. Da vida nervosa nas classes trabalhadoras. Rio de Janeiro: Jorge Zahar Editor; 1986.

50. Montero P. Da doença à desordem. A magia na umbanda. Rio de Janeiro: Graal; 1985.

51. Queiroz MS, Canesqui AM. Famílias trabalhadoras e representações sobre saúde, doença e aspectos institucionais da medicina "oficial" e "popular". Cad Pesq. 1989; 7:1-32.

52. Victora CG , Knauth DR, Hassen MNA. Pesquisa qualitativa em saúde. Porto Alegre: Tomo Editorial; 2000.

53. Ferreira J. Os cuidados do Corpo em vila de classe popular. In: LF Duarte, Leal OF, organizadores. Doenças, sofrimento, perturbação: perspectivas etnográficas. Rio de Janeiro: FIOCRUZ; 1998. p.49-56.

54. Canesqui AM, Nunes ED, Barros MBA, L'Abbate S. Práticas de manutenção da saúde entre trabalhadores da Unicamp. Resumos do 5 Congresso Brasileiro de Saúde Coletiva; 1994; Recife. p.11.

55. Garcia RWD. Práticas e comportamento alimentar no meio urbano: um estudo no centro da cidade de São Paulo. Cad Saúde Pública. 1997; 13(3): 455-76.

56. Garcia RWD. Representações sociais da alimentação e saúde e suas repercussões no comporta- mento alimentar. Physis-Rev Saúde Coletiva. 1997; 7(2):51-68.

57. Scott P. Saúde e pobreza no Recife. Poder, gênero e representações de doenças no Bairro Ibura. Recife: Universidade Federal de Pernambuco. 1966. p.202-15.

58. Boltanski L. As classes sociais e o corpo. Rio de Janeiro: Graal; 1979.

59. Turner V. The ritual process. London: Penguin; 1974.

60. Guimarães AZ. As mulheres e a direção do consumo doméstico. In: Almeida MSK, et al. organizadores. Colcha de retalhos: estudos sobre família no Brasil. São Paulo: Brasiliense; 1983. p.161-84.

61. Assis AMO, Freitas MCS, Oliveira TC, Prado MS, Sampaio LR, Machado AD, et al. Bró, caxixe e ouricuri: estratégias de sobrevivência no semi-árido baiano. Rev Nutr. 1999; 12(2):159-66.

62. Murrieta RSS. O dilema do papa-chibé: consumo alimentar, nutrição e práticas de intervenção na Ilha de Itaqui, baixo Amazonas, Pará. Rev Antrop. 1998; 41(1):97-50.

63. Costa-Neto EM. Restrições e preferências alimentares em comunidades de pescadores do município do Conde. Estado da Bahia. Rev Nutr. 2000; 13(2):117-26.

64. Lèvi-Strauss C. O Pensamento selvagem. São Paulo: Editora Nacional; 1970.

Recebido em: 27/10/2005

Versão final reapresentada em: 30/10/2006 Aprovado em: 22/12/2006 